\title{
Measuring the fire in their hearts: assessing passion for the profession among students pursuing surgical careers
}

\author{
Aimee K. Gardner ${ }^{1,2} \cdot$ Ross E. Willis ${ }^{3}$ \\ Received: 20 October 2021 / Revised: 4 January 2022 / Accepted: 18 January 2022 / Published online: 28 February 2022 \\ (c) The Author(s), under exclusive licence to Association for Surgical Education 2022
}

\begin{abstract}
Background Leaders in surgery have posited that passion for the surgery profession is diminishing among entering trainees, and that its scarcity is related to the high levels of attrition observed in general surgery training. This study explores trends in passion for the profession among applicants to general surgery training.

Methods Applicants to a large midwestern academic general surgery program were invited to complete a voluntary, anonymous 12-item Passion for Surgery Index (PSI) as part of their supplementary application package during the 2020-2021 and 2021-2022 residency selection seasons. The PSI is adapted from a generic work-related passion index and is based on the dualistic model of passion, organizing scores into harmonious passion and consuming passion. Applicants completed the index on a stand-alone website which automatically generated results pertaining to overall passion, harmonious passion, and consuming passion for the surgery profession. Applicants were provided with their results and provided feedback.

Results Sixty-one percent (871/1428) of invited applicants completed the PSI. Approximately 67.4\% $(N=587)$ of these applicants reported an overall high level of passion for surgery, while $31.1 \%(N=271)$ reported a moderate level and the remaining $1.5 \%(N=13)$ reported a low level. When comparing the two different types of passion, the vast majority of applicants $(92.8 \% ; N=808)$ reported a high level of harmonious passion and only $7.1 \%(N=62)$ reported a moderate level of harmonious passion. The results for consuming passion were much more varied, with $36.9 \%(N=321)$ reporting a high level, $47.5 \%(N=414)$ reporting a moderate level, and 15.6\% $(N=136)$ reporting a low level of consuming passion for the profession.

Discussion These results suggest that there is substantial variation in passion for the profession among those pursuing a career in surgery. While the majority of applicants reported a high level of harmonious passion for surgery, less than half of applicants reported a high level of consuming passion for surgery. This variability in consuming passion among entering trainees is concerning, as individuals with low or only moderate passion for the profession may not have the motivation or drive to persist in demanding training environments.
\end{abstract}

Keywords Passion $\cdot$ Selection $\cdot$ Residency $\cdot$ Match $\cdot$ Career $\cdot$ Burnout $\cdot$ Satisfaction

\section{Introduction}

Aimee K. Gardner

aimee.gardner@bcm.edu

1 Baylor College of Medicine, MS: BCM115, DeBakey Building, M108K, One Baylor Plaza, Houston, TX 77030, USA

2 SurgWise Consulting, Houston, TX, USA

3 University of Texas Health San Antonio, San Antonio, TX, USA

Passion for work has been defined as a "strong inclination toward an activity that people like, that they find important, and in which they invest their time and energy" [1]. Individuals with increased passion for their careers have been found to expend increased effort, be more persistent, and experience higher levels of enthusiasm [2]. Furthermore, passion for work has been positively related to job creativity [3], the experience of "flow," satisfaction, and negatively associated with burnout within the healthcare workforce [4, 5]. Researchers have posited that passion for a profession has these beneficial outcomes at work, because passionate 
individuals associate more of their self-identity with their profession, and this internalization leads workers to invest a significant amount of time and energy into their job [1].

Leaders in surgical education have posited that passion for the surgical profession is diminishing among entering trainees [6]. They point to the high rates of attrition for trainees [7] and high levels of dissatisfaction among those in practice [8] as evidence of this decline in passion. Reasons vary, but authors have suggested that the hypothesized decline in passion among surgical trainees stems from entering trainees not obtaining an accurate realistic preview of surgical training during medical school, students overestimating their ability to adapt to demanding surgical schedules, and/or lack of role models generating and maintaining passion among trainees [6]. Kavic [9] has suggested that passion for surgery is the single most important attribute that will determine if an applicant is a good candidate for a surgical training position. Given the plethora of beneficial outcomes associated with work passion demonstrated in the literature, combined with the importance surgical educators have placed upon it for success in and satisfaction with surgical training, it is critical that we have some methodology by which to measure it.

Vallerand's dualistic model of work passion is the most well known within the psychology literature [1]. According to this framework, harmonious passion is the product of willingly and happily engaging in an activity for the sole purpose of enjoyment. Consuming (or obsessive) passion, on the other hand, is the product of engaging in an activity, because it brings a sense of self-identity (e.g., social acceptance, self-esteem) or uncontrollable excitement. In contrast with harmonious passion, consuming passion is intricately integrated with an individual's sense of identity. Vallerand's research demonstrated that harmonious passion was related to positive attitudes during and after an activity, and that being prevented from engaging in the activity does not necessarily result in negative attitudes. In contrast, individuals with high levels of consuming passion will experience negative attitudes if kept away from the activity that they so enjoy.

The goal of this study is to explore the prevalence of passion for the surgical profession among medical students pursuing surgical careers. As researchers have noted that not all passion is created equal, and that two types of passionconsuming and harmonious - can have differential impact on work-related outcomes, we explore the pervasiveness of both among entering surgery candidates. We are hopeful this exploratory work can serve as a foundation for future studies aiming to quantify and correlate passion levels among surgery candidates and trainees.

\section{Methods}

Applicants to a large midwestern academic general surgery program were invited to complete a voluntary, anonymous 12-item Passion for Surgery Index (PSI) as part of their supplementary application package during the 2020-2021 and 2021-2022 residency selection seasons. The PSI was minimally adapted by the authors (e.g., replacing "profession" or "activity" with "career in surgery") from a generic work-related passion index and is based on the dualistic model of passion [10], organizing scores into harmonious passion and consuming passion. Example items include, "The new things I discover about a career in surgery allow me to appreciate it even more" (harmonious) and "I cannot imagine pursuing a career other than surgery" (consuming). All items were completed along a 1 (do not agree at all) to 7 (very strongly agree) Likert-type scale. Responses were collated into a score for harmonious passion, consuming passion, and an overall passion score that factored in responses to all items. Results were categorized into low, moderate, and high based on relation to the bottom (do not agree at all, very slightly agree), middle (slightly agree, moderately agree, mostly agree), and top (strongly agree, very strongly agree) response anchors.

Applicants were provided an introduction to the purposes of the PSI (Fig. 1) and invited to voluntarily complete the index on a stand-alone website not connected to their name or other application data. After completing the PSI, results were automatically generated pertaining to overall passion, harmonious passion, and consuming passion for the surgery profession. Applicants were provided a description associated with their results and resources for further reading [1, 11]. Opportunities to submit dichotomous (happy face/sad face) and open text feedback were also provided.

SPSS 28 was used to compile basic descriptives, including frequencies, means, and standard deviations.

\section{Results}

Sixty-one percent (871/1428) of invited applicants completed the PSI, representing approximately $25 \%$ of all MD applicants to general surgery during each season. As these data were unassociated with application data, no other demographics or descriptives of participants are available.

Figure 2 shows the frequency of passion results. Approximately $67.4 \%(N=587)$ of these applicants reported an overall high level of passion for surgery, while $31.1 \%(N=271)$ reported a moderate level and the remaining $1.5 \%(N=13)$ reported a low level.

When comparing the two different types of passion, the vast majority of applicants $(92.8 \% ; N=808)$ reported a high 


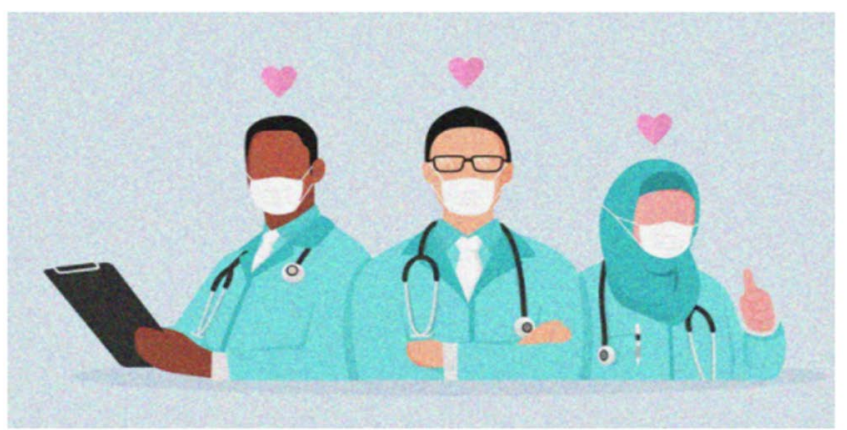

\footnotetext{
Passion for surgery has been described as having a "fire in our hearts." The practice of the great art and science of surgery should bring with it an excitement and yearning that is obvious every day in the work we do, in our relationships with patients, and in the way we live our lives. Without this passion, the work can result in a sense of joyless perseverance. Becoming a surgeon involves long hours, demanding work, and often personal sacrifices. If one is to pursue this line of work for long hours over several years, and even a lifetime, one must love the activity dearly and have the desire to pursue it especially when times are rough. Passion is the resource that fuels us when we are otherwise running on empty.

The website below provides you with an opportunity to complete a short scale about your passion for pursuing a career in surgery. You will be able to see your results along with a brief description and resources for further reading. This scale is by no means scientific, and the results are not meant to dissuade you from pursuing any career path. These results are only meant to serve as an introspective exercise for you to reflect upon your career plans and ensure surgery will offer you a fulfilling, happy career. The majority of surgery residents are in the prime of their life when they begin residency, and we want to make sure that these years are the most rewarding, satisfying, and intellectually fulfilling for you.

Your responses to the Passion Index will NOT be provided to any residency program. These results are meant to help you in your journey and will only be seen by you.

Do you understand that completing the scale is voluntary and that your results will not be provided to any programs to which you are applying?
}

Fig. 1 Introduction to the Passion for Surgery Index

Fig. 2 Passion levels by category

\section{Overall Passion
Harmonious
Passion
Consuming Passion

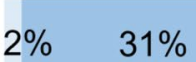

$67 \%$ level of harmonious passion and only $7.1 \%(N=62)$ reported a moderate level of harmonious passion. Harmonious items that demonstrated the highest mean values included, "The new things I discover about a career in surgery allow me to appreciate it even more" (mean 6.54; SD 0.68) and "Being a surgeon reflects the qualities I like about myself" (mean 6.39, SD 0.83).

The results for consuming passion were much more varied, with $36.9 \%(N=321)$ reporting a high level, $47.5 \%$ $(N=414)$ reporting a moderate level, and $15.6 \%(N=136)$ reporting a low level of consuming passion for the profession. Consuming items that demonstrated the highest mean values included, "I cannot imagine pursuing a career other than surgery" (mean 6.02; SD 1.33) and "My urge to pursue surgery is so strong that I cannot help from thinking about it" (mean 5.96; SD 1.27). Over a quarter of applicants $(26.1 \%)$ at least moderately agreed that others in their life were pushing them toward a surgical career.

Two hundred and seventy-three applicants who completed the PSI (31.3\%) provided feedback. Ninety-three percent $(255 / 273)$ of these individuals indicated they were satisfied with the experience. Table 1 displays a sampling of comments to the open response question organized by theme. 
Table 1 Themes from the open response feedback survey

\begin{tabular}{|c|c|}
\hline Theme & Example comments \\
\hline Informative & $\begin{array}{l}\text { "I thought this was an interesting exercise. I also think the analysis is pretty spot on for me. I was relieved } \\
\text { to see that overall I have moderate passion because I consider myself a pretty level-headed guy" } \\
\text { "This is extremely helpful for an introspective understanding of my passion and motivation for pursuing a } \\
\text { career in surgery" } \\
\text { "This exercise was very compelling. It made me think about how I truly feel about becoming a surgeon and } \\
\text { allowed me to dig deep to realize that I truly am passionate about this field" } \\
\text { "This helped me put things into perspective" }\end{array}$ \\
\hline Fun & $\begin{array}{l}\text { "This was fun. I read the articles too because they were very interesting" } \\
\text { "Very interesting. Thank you!" }\end{array}$ \\
\hline Timing & $\begin{array}{l}\text { "Perhaps consider offering this survey before applying to residency programs in ERAS" } \\
\text { "I think I have a lot of conviction to be in general surgery, but at the moment...I'm also a bit burned out..." }\end{array}$ \\
\hline Anonymity & $\begin{array}{l}\text { "I appreciate that these answers are confidential and I answered truthfully. It is telling that I would have } \\
\text { felt pressure to rate my passion levels higher in a non-confidential test. There have been times when I do } \\
\text { doubt my interest in surgery, especially on 'bad' days. The concept of harmonious passion is new for me } \\
\text { and encouraging" } \\
\text { "I'm glad to have been able to do this in an anonymous way. I think the results that I have low passion for } \\
\text { put what was in the back of my head right in front of me in a more objective manner" }\end{array}$ \\
\hline
\end{tabular}

\section{Discussion}

These findings highlight that while the majority of applicants to general surgery have relatively high levels of passion for the profession, there is a substantial amount of variability across applicants. Furthermore, these data support the dualistic model of passion by demonstrating that a considerable number of individuals can have high harmonious passion for the surgery profession (e.g., think it is interesting), while also having more tempered opinions about the extent to which being a surgeon is central to their identity or the only path for them. In the psychology literature, consuming passion has often been considered the "lesser" of the two passions, as it is somewhat described as reflecting an almost compulsive drive to engage in the activity. However, this may not be the case for an intense and demanding profession like surgery. A high level of consuming passion may be necessary to manage the rigors and expectations of this high stakes profession. Indeed, other work measuring the impact of passion among healthcare teams has shown that passion can boost physician's energy to tackle challenging circumstances and recover successfully from them, thereby boosting individual performance [12]. For a specialty that often provides the advice of, "If you can see yourself doing anything other than surgery, than do the other thing," these findings may be especially helpful. In fact, one of the items on the consuming passion scale, "I cannot imagine pursuing a career other than surgery" directly reflects the aforementioned sentiment. In our sample, only about half of applicants indicated they "very strongly agreed" with this statement.

While we cannot speculate as to the explanations of this observed variability, these data do align with other indicators of "low passion" for the surgery profession. For example, the most recent application data show that approximately a quarter of all applicants to surgery positions also apply to other specialties [13]. Other work has similarly shown that a significant percentage of individuals who match within surgery have indicated that surgery was their "nonpreferred" specialty [14].

Results from the open responses reveals that applicants valued the opportunity to receive feedback on their passion levels. Applicants indicated it was an informative exercise, with a variety of reactions to their results. As shown in Table 1, one applicant indicated he was satisfied with receiving his moderate level results, because it accurately reflects his self-perception of himself as a "level-headed guy." Others reported the results provided tangible data to support their career decisions. Others reported it was simply a fun exercise and they enjoyed the experience. Finally, the themes of timing and anonymity provide guidance to future educators seeking to implement a similar exercise from a career advising or feedback standpoint. Some applicants indicated that they would have valued participating in this exercise at different time points, such as before selecting a specialty or at another point in time in which burnout might be lower. Multiple applicants also indicated that they appreciated an opportunity to complete the passion index in an anonymous fashion, as they would otherwise feel pressure to inflate their responses. Thus, results from the open response feedback provide insight into how applicants interpreted their results and guidance for future educators hoping to implement similar exercises.

As a field, the surgery specialty needs to ensure that not only are those accepted in sincerely interested and committed to the profession, but also that we are nurturing passion among entering trainees. Given the plethora of data showing the relationship between work passion and positive 
outcomes, combined with the literature documenting the risks of dissatisfaction, low job commitment, and burnout when individuals are in professions of which they are not highly passionate, we should make this a priority. But how do we spark passion and maintain it within the surgery profession? One answer suggested in the surgical literature is through role modeling [9]; surgeons in training and practice can model passion and joy. In fact, one of the most cited factors that impacts student interest in surgery is job satisfaction among residents and attendings [15]. Others have emphasized the contagious effect of role models as well, with statements such as, "Feelings do beget feelings, and great feelings beget great feelings"[9]. Other methods to spark passion for the surgery profession might include intentional creation of venues to celebrate the meaning and impact of the work surgeons do. For example, the traditional Morbidity and Mortality conference venue could be extended to include another 'M' for "Meaning," which could include highlighting cases that were considered especially impactful and reflective of why one joined the surgery profession.

This study has a number of limitations upon which future work can build. These data reflect solely self-reported data collected at one point in time from a voluntary sample of applicants to one residency program. As such, there are no other data to which these data can be tied, and no ability to follow-up upon these data to know the relationship with other important outcomes. Further, while these data are built upon a strong foundation within the psychology literature, this is the first study to examine passion from a theoretical framework in surgery. Thus, the extent to which this theoretical framework fully applies is limited. Future work should explore the extent to which responses to the PSI are linked to burnout, career satisfaction, and attrition. Furthermore, an exploration of how passion for the profession increases or decreases as individuals become more ingrained in surgical training would be fruitful. Nor do we know how passion may be impacted by the recent disruptions to clinical training among these cohorts as a result of COVID-19. Although we did not see any differences in passion between the 2020-2021 and 2021-2022 applicant cohorts, it is possible that even a few months of disruption during the third or fourth year of medical school can impact the extent to which passion for the profession is able to develop. Finally, we do not know if a minimum level of passion for the profession is enough. For example, can those interested in surgery become even more passionate through encouragement or does there need to be a certain level of passion upon entry for trainees to have happy and productive careers? In contrast, is there a "the higher they are, the harder they fall" phenomenon within the profession, wherein those at the most peak levels of passion are at risk of even higher burnout and dissatisfaction when they experience the reality of surgical training? Future studies should explore these processes.

\section{Conclusion}

While the majority of applicants to general surgery have high relatively high levels of passion for the profession, there is a substantial amount of variability across applicants. The surgery profession should identify systematic opportunities to measure and facilitate passion for the profession.

Data availability The datasets generated during and/or analyzed during the current study are available from the corresponding author on reasonable request.

\section{References}

1. Vallerand RJ, Blanchard C, Mageau GA, Koestner R, Rattelle C, Leondard M, Gagne M, Marsolais J. On obsessive and harmonious passion. J Person Social Psychol. 2003;85:756-67.

2. Cardon MS, Zietsma C, Saparito P, Matherne B, Davis C. A tale of passion: new insights into entrepreneurship from a parenthood metaphor. J Bus Ventur. 2005;23:23-45.

3. Liu D, Chen X-P, Yao X. From autonomy to creativity: a multilevel investigation of the mediating role of harmonious passion. $\mathrm{J}$ Appl Psychol. 2011;96:294-309.

4. Carbonneau N, Vallerand RJ, Fernet C, Guay F. The role of passion for teaching in intra and interpersonal outcomes. J Educ Psychol. 2008;100:977-87.

5. Vallerand RJ, Paguet Y, Philippe FL, Charest J. On the role of passion in burnout: a process model. J Person. 2010;78:289-312.

6. Singletary SE. A fire in our hearts: passion and the art of surgery. Ann Surg Oncol. 2010;17:364-70. https://doi.org/10.1245/ s10434-009-0732-x.

7. Yeo HL, Abelson JS, Symer MM, Mao J, Michelassi F, Bell R, Sedrakyan A, Sosa JA. Association of time to attrition in surgical residency with individual resident and programmatic factors. JAMA Surg. 2018;153:511-7.

8. Leigh JP, Kravitz RL, Schembri M, Samuels SJ, Mobley S. Physician career satisfaction across specialties. Arch Intern Med. 2002;162:1577-84.

9. Kavic MS. Surgery, passion, and the medical student. J Soc Lap Rob Surgeons. 1999;3f:169-70.

10 Vallerand RJ. On passion for life activities: the dualistic model of passion. In: Zanna MP, editor. Advances in experimental and social psychology, vol. 42. New York: Academic Press; 2008. p. 97-193.

11. Vallerand RJ. On the psychology of passion: in search of what makes people's lives most worth living. Canad Psychol. 2008;49:1-13.

12. Salas-Vallina A, Rofcanin Y, Las HM. Building resilience and performance in turbulent times: the influence of shared leadership and passion at work across levels. Bus Res Q. 2021. https://doi. org/10.1177/23409444211035138.

13. ERAS Statistics 2020. https://www.aamc.org/data-reports/inter active-data/eras-statistics-data. Accessed 27 Mar 2021.

14. Andriole DA, Jeffe DB, Klingensmith M. Do general surgery applicants really want to be general surgeons? Curr Surg. 2006;63:145-50.

15. Berman L, Rosenthal MS, Curry LA, Evans LV, Gusberg RJ. Attracting surgical clerks to surgical careers: Role models, mentoring, and engagement in the operating room. J Am Coll Surg. 2008:207:793-800. 